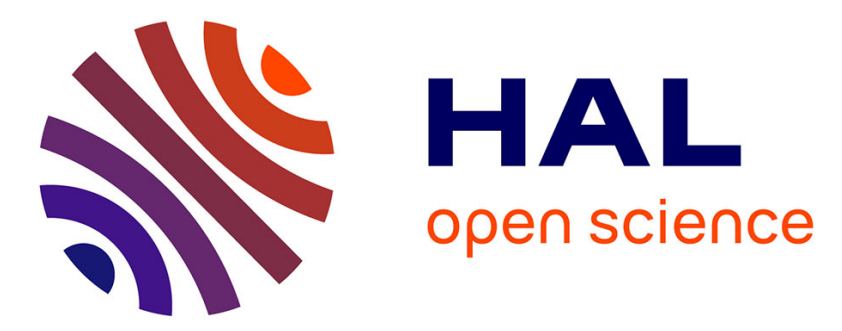

\title{
Enhanced cardiac differentiation of mouse embryonic stem cells by use of the slow-turning, lateral vessel (STLV) bioreactor
}

\author{
Sasitorn Rungarunlert, Nuttha Klincumhom, Istvan Bock, Csilla Nemes, \\ Mongkol Techakumphu, Melinda K. Pirity, Andras Dinnyes
}

\section{To cite this version:}

Sasitorn Rungarunlert, Nuttha Klincumhom, Istvan Bock, Csilla Nemes, Mongkol Techakumphu, et al.. Enhanced cardiac differentiation of mouse embryonic stem cells by use of the slow-turning, lateral vessel (STLV) bioreactor. Biotechnology Letters, 2011, 33 (8), pp.1565-1573. 10.1007/s10529-0110614-8 . hal-00686172

\section{HAL Id: hal-00686172 \\ https://hal.science/hal-00686172}

Submitted on 8 Apr 2012

HAL is a multi-disciplinary open access archive for the deposit and dissemination of scientific research documents, whether they are published or not. The documents may come from teaching and research institutions in France or abroad, or from public or private research centers.
L'archive ouverte pluridisciplinaire HAL, est destinée au dépôt et à la diffusion de documents scientifiques de niveau recherche, publiés ou non, émanant des établissements d'enseignement et de recherche français ou étrangers, des laboratoires publics ou privés. 


\section{Section: Animal Cell Technology}

Enhanced cardiac differentiation of mouse embryonic stem cells by use of the slow-turning, lateral vessel (STLV) bioreactor

Sasitorn Rungarunlert • Nuttha Klincumhom • Istvan Bock • Csilla Nemes • Mongkol Techakumphu • Melinda K.

Pirity • Andras Dinnyes

S. Rungarunlert $\bullet$ N. Klincumhom $\bullet$ I. Bock $\bullet$ Cs. Nemes $\bullet$ MK. Pirity $\bullet$ A. Dinnyes

BioTalentum Ltd., Aulich Lajos u. 26. H-2100, Godollo, Hungary

S. Rungarunlert $\bullet$ N. Klincumhom $\bullet$ M. Techakumphu

Department of Obstetrics, Gynaecology and Reproduction, Faculty of Veterinary Science, Chulalongkorn University, Bangkok, 10330 Thailand

I. Bock • A. Dinnyes

Molecular Animal Biotechnology Laboratory, Szent Istvan University, H-2100 Gödöllö, Hungary

Corresponding author: andras.dinnyes@biotalentum.hu; Phone: +36/20/510-9632, Fax: +36/28/526-151

Emails:

Sasitorn Rungarunlert•nut_vs@yahoo.com

Nuttha Klincumhom • nuttha.klincumhom@biotalentum.hu

Istvan Bock • istvan.bock@biotalentum.hu

Csilla Nemes • csilla.nemes@ biotalentum.hu

Mongkol Techakumphu • Mongkol.T@ chula.ac.th

Melinda K. Pirity • melinda.pirity@biotalentum.hu 


\begin{abstract}
Embryoid body (EB) formation is a common intermediate during in vitro differentiation of pluripotent stem cells into specialized cell types. We have optimized the slow-turning, lateral vessel (STLV) for large scale and homogenous EB production from mouse embryonic stem cells. The effects of inoculating different cell numbers, time of EB adherence to gelatin-coated dishes, and rotation speed for optimal EB formation and cardiac differentiation were investigated. Using $3 \times 10^{5}$ cells $/ \mathrm{ml}, 10 \mathrm{rpm}$ rotary speed and plating of EBs onto gelatin-coated surfaces three days after culture, were the best parameters for optimal size and EB quality on consequent cardiac differentiation. These optimized parameters enrich cardiac differentiation in ES cells when using the STLV method.
\end{abstract}

\title{
Keywords
}

Bioreactor; Cardiomyocyte; Embryoid body; Embryonic stem cells; Slow turning lateral vessel 


\section{Introduction}

Embryoid body (EB) formation from embryonic stem (ES) cells (Evans \& Kaufman et al. 1981; Martin 1981) is a common method for producing different cell lineages for further applications. The cells found within EBs are typically heterogeneous and their subsequent differentiation may be unpredictable, which is one of the major drawbacks for further application. Efforts to manipulate the EB environment and subsequent ES cell differentiation have focused primarily on either controlling media composition (Schuldiner et al. 2000) or assembly of EBs using different culture methods (Hopfl et al. 2004). The three basic methods are: (i) Hanging drop (HD) (Shamblott et al. 2002) (Chen et al. 2010), (ii) static suspension culture (SSC) (Dang et al. 2002) and (iii) bioreactors bioreactors (Yirme et al. 2008). The latter technique can be divided further to different rotary cell culture system (RCCS) technologies which is comprised of a slow turning lateral vessel (STLV) and a high aspect rotating vessel (HARV) (Gerecht-Nir et al. 2004; Lu, et al. 2008; Hwang et al. 2009). Bioreactors have been reported to increase the efficiency of EB formation and differentiation of stem cells into the three germ layers of embryonic development. However, the influence of dynamic culture parameters (i.e. speed, cell seeding density, etc.), specifically for spontaneous cardiac differentiation of ES cells, has not yet been reported. In the current study, we used the mouse ES cell line HM1 from 129Sv/Ola genetic background and have investigated the effects of, inoculating cell number, rotation speed and the time of EB adherence to gelatin-coated dishes for optimal EB formation and subsequent cardiac differentiation in STLV rotating bioreactor. The STLV method confers extremely low fluid shear stress and oxygenation by diffusion. This method also allows creation of a more uniform and homogenous cell population of EBs that is more favorable for subsequent cell differentiation, compared with classical HD or SSC methods.

\section{Materials and methods}

Materials and cell culture reagents

All chemicals were purchased from Sigma and culture reagents were purchased from Invitrogen unless otherwise specified.

In vitro cell culture 
The embryonic stem (ES) cell line HM1; 129Sv/Ola genetic background was cultured on feeder layers of mitomycin C-inactivated mouse embryonic fibroblasts (MEFs; ICR genetic background) as described earlier (Magin et al. 1992). Cells in STLVs were maintained in ES medium consisting of Dulbecco's Modified Eagle's Medium (DMEM), 15\% (v/v) fetal bovine serum (FBS, Sera Laboratories International, West Sussex, RH17 5PB, UK) supplemented with or without (for in vitro differentiation assays) 2,000 U mouse leukemia inhibitory factor/ml (LIF, ESGRO, Chemicon International), $0.1 \mathrm{mM}$ non-essential amino acids (NEAA), $0.1 \mathrm{mM} \beta$-mercaptoethanol ( $\beta$-ME) and $50 \mathrm{U}$ penicillin/ml, $50 \mu \mathrm{g}$ streptomycin/ $\mathrm{ml}$.

Culturing cells in slow-turning, lateral vessel (STLV)

STLV (The Rotary Cell Culture System RCCS-1/RCCS-4; Synthecon, Incorporated, Houston, Texas) was prepared as manufacturers recommendations. Briefly, the STLV were washed 3 times with cleaning solution, rinsed 3 times with deionized water and soaked in $70 \%$ (w/v) alcohol over night and air-dried. Finally, the vessels were autoclaved for $1 \mathrm{~h}$ before every use. Monolayer cultures of ES cells were dissociated using $0.05 \%$ trypsin/EDTA solution to get a single cell suspension. Cells were inoculated in a $110 \mathrm{ml}$ STLV. STLV cultures of EBs were set 10 rpm, except during studies in which rotation speeds of 15 and $20 \mathrm{rpm}$ were also examined. EBs were maintained for up to 5 days in suspension. Medium was changed every 2 days by allowing EBs to sediment in the STLV, aspirating the old medium, and re-suspending the EBs in fresh medium. EBs were collected at different time points (D2-D5) for evaluating gross morphology, size and yield.

Morphometric analysis

For size analysis, the diameter average was calculated by measuring the large and small diagonals of 20 representative EBs. The results of the assessment from three independent experiments are presented. Phase contrast images of EBs were acquired using an Olympus IX71 inverted microscope with an attached Olympus DP 70 digital camera (Olympus Europa Holding $\mathrm{GmbH}$, Germany) and analyzed using ImageJ image analysis software (http://rsb.info.nih. gov/ij) to measure the cross-sectional area of the EBs.

Differentiation of ES cells to cardiomyocytes 
Individual EBs were plated onto gelatin coated dishes at different time points (day2-5; D2-5) into separate wells of a 24-well plate for spontaneous cardiomyocyte differentiation. Differentiation medium consisted of undifferentiated medium without LIF. EBs were cultured for 14 or 21 days and observed daily under a phase-contrast microscope.

Quantification of EB beating activity

Cardiac beating activity was evaluated by grading the area of beating foci and the beating rate as follows: Grade 1 , one area of beating foci with slow beating rate; Grade 2, two areas of beating foci with slow beating rate; Grade 3, more than two areas of beating foci with fast beating rate; Grade 4, whole area of beating foci with fast beating rate. Forty-eight EBs were counted for each treatment and experiments were performed in triplicate.

RT-qPCR

Total RNA was isolated using the RNeasy Mini Kit (Qiagen) according to manufacturer's instructions. For each sample, 500 ng RNA was reverse transcribed using the SuperScript VILO cDNA Synthesis Kit (Invitrogen, as per the manufacturer's instructions. Quantitative RT-PCR reactions were performed as previously described (Kobolak, et al. 2009). Gapdh was used as a reference gene. PCR reactions were carried out on a Rotor-Gene Q real-time PCR machine (Qiagen, Hilden, Germany). The Relative Expression Software Tool 2008 V2.0.7 was applied to determine differences in expression of the studied genes.

Immunostaining

Whole EBs were plated onto $0.1 \%$ gelatin-coated coverslips, fixed with $4 \%$ paraformaldehyde for 15 min at room temperature and processed according to the primary antibody manufacturer's instructions. Antibodies: cardiac troponin T (cTnT, diluted 1:200; Abcam, UK, ab33589), Alexa Fluor 594 (diluted 1:2.000; Invitrogen, A11005). The EBs were fluorescently imaged and analyzed by using Digital Image Processing Software (AxioVision 4.8.1, Carl Zeiss MicroImaging GmbH, Germany).

Statistical analysis 
Data are expressed as mean \pm SEM and include at least three independent experiments. Statistical analyses were conducted using the Student's $t$ test. A P $<0.05$ was considered statistically significant.

\section{Results and discussion}

Effect of cell seeding density on in vitro EB formation

ES cells were maintained in an undifferentiated state on MEFs (see Materials and methods). Their gross morphology corresponded to typical ES cell morphology including, round-shaped, compact, and shiny colonies (Fig. 1a). In order to determine the optimal conditions for EB formation in the STLV culture system, EBs were generated by inoculating cells at: $10^{5}$ (STLV1); $2 \times 10^{5}$ (STLV2); $3 \times 10^{5}$ (STLV3) and $5 \times 10^{5}$ (STLV4) cells per ml to STLV culture. After inoculation (D0) EBs were cultured in STLV systems and samples were collected at different time points (D2-D5) (Fig. 1b) and analyzed based on their gross morphology (Fig. 1c), size (Fig. 1d) and yield (Fig. 1e). The most uniform size EBs formed from STLV3 and STLV4 at all examined time points (Fig. 1c; STLV3, STLV4, at D2, D3, D4, D5). Based on gross morphology, the EBs were consistent in size, morphologically similar and homogeneous (Fig. 1c). STLV1 and STLV2 cultures appeared to form regular, spherical EBs, only after 2 days (with size of $299 \pm 12$ and $401 \pm 16.4 \mu \mathrm{m}$ (Fig 1c; STLV1 and STLV2: D3 and Fig. 1d respectively), whereas STLV3 and STLV4 formed them earlier, on day2 (464 \pm 7.8 and $463 \pm 8.2 \mu \mathrm{m})$ (Fig. 1c; STLV3 and STLV4; D2 and Fig. 1d respectively). Noticeably, STLV1 and STLV2 produced less homogenous EBs, with less defined cell aggregates at all examined days (D2-5) (Fig. 1c) and STLV1 exhibited the smallest EBs for all days examined. The yield of EB production in different STLV conditions was determined by quantifying the percentage of total cells that incorporated into EBs, as opposed to cells that remained free in suspension or adhered to the culture dish (Fig. 1e). The tendency showed that STLV3 culture conditions result in the highest yield of formed EBs. Importantly, the STLV1 and STLV 2 bioreactors contained a mixture of small aggregates (STLV1: 37.5, 118.5, 110.5, $143.6 \mu \mathrm{m}$ on D2, D3, D4 and D5 respectively; STLV2: 163.2, 185.2, 131.2, $253.9 \mu \mathrm{m}$ on D2, D3, D4 and D5, respectively) and large aggregates (STLV1: 260.3, 502.6, 559.9 and $671.5 \mu \mathrm{m}$ on D2, D3, D4 and D5, respectively; STLV2: 706.6, 661.5, 745.9 and $768.8 \mu \mathrm{m}$ on D2, D3, D4 and D5, respectively) (Fig.1c; STLV1, STLV2 on D2, D3 and also on D4 and D5), whilst STLV3 and STLV4 gave a more homogenous, uniformly sized EB population with little or no 
variation (Fig.1c; STLS3, STLV4 on D2, D3, D4 and D5). Since STLV3 and STLV4 culture conditions produced larger-sized and better yields of EBs and the gross morphology of EBs were the most uniform and homogeneous at almost all examined time points, we chose these two STLV conditions to proceed further with the following experiments.

The effect of the rotary speed of STLV on the efficiency of EB production

To study the effect of rotary speed on EB formation, $3 \times 10^{5}$ (STLV3) cells were inoculated in STLV systems using different rotary speeds $(10,15$ and $20 \mathrm{rpm})($ Fig. 2). The $10 \mathrm{rpm}$ rotary speed was found to facilitate the greatest incorporation of ES cells within EBs. Normalizing ES cells incorporation to the $110 \mathrm{ml}$ STLV volume demonstrated that EBs formed at other rpms as well, however with lower incorporation rates. Importantly, EBs generated at 10 rpm rotary speed remained similar in size and slightly larger (roughly $442 \pm 6.4 \mu \mathrm{m}$ diam.) (Fig. 2b) than EBs formed at other rpm. The rotary speed did not seem to have a major effect on the yield of EB production (Fig. 2c). Therefore, the relatively large number of EBs obtained at $10 \mathrm{rpm}$, and the more efficient formation of EBs (indicated by fewer individual cells remaining in suspension) were the determining factors for use of this rotary speed for all subsequent experiments performed in this study.

Effect of time of EB plating, on in vitro cardiac differentiation

Individual EBs, produced in STLV3 and STLV4, were plated onto gelatin-coated dishes (see materials and methods) for spontaneous cardiomyocyte differentiation. Differentiated EBs were cultured for 14 days and observed daily under a bright-field microscope. Forty-eight EBs were counted for each treatment group and from three replicates. The number of beating EBs are presented as a percentage of the total number of EBs plated (Fig. 3a, 3b, 3c and 3d). Spontaneously contracting EBs began to appear as early as day 7 in the STLV3/D2 (Fig. 3a), STLV3/D3 (Fig. 3b) and STLV4/D2 groups (Fig. 3a). By day 10, plated EBs formed spontaneously beating colonies in the STLV3/D2 (Fig. 3a), STLV3/D3 (Fig. 3b) and STLV4/D2 groups (Fig. 3a). EBs plated on D2 and D3 had higher percentages of beating areas, then if they were plated later (D4 and D5) (Fig. 3c and Fig. 3d). This indicates that the day of plating 
EBs onto gelatinized dishes is critical for this process and that EBs plated on D3 or earlier, are optimal for further applications.

The quantity of cardiac beating was also evaluated by grading the cardiac beating (Fig. 3e-h). Grading was performed based on the size of the beating area and the rate of beating (see materials and methods). The grading revealed that STLV3 EBs plated on either D2 or D3 gave the best results: i.e. the highest number and fastest beating contractile areas. The STLV4 EBs could also form cardiomyocytes, however scored lower, according to the grading scale. This suggests that EBs plated on either D2 or D3 from STLV3 generated EB are superior for producing rhythmically beating cardiomyocytes.

Quantitative RT-PCR gene expression analysis of EBs produced in STLV

The induction of cardiac differentiation was further analysed by quantitative real time polymerase chain reaction (RT-qPCR; Fig. 4). RNA was extracted from EBs derived from STLV at days 3, 7, 14 and 21 (D3, D7, D14 and D21) and gene expression of standard pluripotency (e.g. Pou5f1/Oct4; Fig. 4a) early (Nkx2.5; Fig. 4b) and late (Tnnt2 (Fig. 4c), Myh6 (Fig. 4d), Myl2 (Fig. 4e); Nppa (Fig. 4f) cardiac and early mesoderm inducing factor Brachyury (Fig. 4g) markers were assayed. Figure 4 shows examined transcripts from the STLV3 culture conditions at D3, D7, D14 and D21. The level of Pou5f1/Oct4 (gene expressed by cells in the ICM as well as the epiblast) was high in undifferentiated cells and by D7, diminished to almost undetectable levels at all examined samples (Fig. 4a). In parallel, many of the genes that were up-regulated in EBs were phenotypic markers of cardiac gene expression: Nkx2.5 (Fig. 4b), Tnnt2 (Fig. 4c), Myh6 (Fig. 4d), Myl2 (Fig. 4e); Nppa (Fig. 4f). Thus, Nkx2.5 gene expression, which marks early cardiac precursors (Schwartz et al. 1999 \& Ranganayakulu et al. 1998) peaked by D7 and stayed high until D14. During mouse embryogenesis Nkx2.5 is expressed abundantly when the heart forms and in standard in vitro differentiation assays, peaks at D5-8. In our optimized STLV system, the expression of Nkx2.5 seems to be prolonged: i.e. the level is still detectable even at D14, suggesting that cardiac precursors are present even during late time points. One explanation might be that the optimized STLV conditions ensure a gradual and permanent microenvironment and equalized nutrient support achieved by continuous rotation. This may accelerate and stabilize the formation of more stable EBs, with no significant decrease in constituent ES cell viability. Brachyury (T) is a gene crucial to induce early mesoderm formation and is up-regulated in the primitive streak of the developing 
embryo (Dobrovolskaia-Zavadskaia et al. 1927). As expected, the level of Brachyury mRNA was elevated at the beginning of differentiation (D3-7; Fig. 4g) and showed decaying expression thereafter. The transcript level of Brachyury usually peaks at D3-4 in in vitro cardiac differentiation assays, then decreases thereafter. In our assays, the level of Brachyury decreased gradually without any peak, suggesting there were no subsets of cells in our STLVderived EBs entering the primitive streak-stage but rather, cells within EBs gradually became engaged towards different lineages (e.g. cardiac). One of the advantages of bioreactor- derived EBs is that they consist of more homogenous cell populations and do not contain minor subpopulation of cells as observed in other culture methods (e.g. SSC) (Ref). In agreement with this, at the later time point of spontaneous cardiac differentiation, cardiac markers became prominent. The expression of Tnnt2 (Fig. 4c), Myh6 (Fig. 4d) and Myl2 (Fig. 4e) (which are cardiomyocyte structural constituents) peaked by D14. Atrial natriuretic peptide Nppa (Fig. 4f), encoded by Nppa, regulates multiple ion channels in atrial cardiomyocytes and in our study, was also highly expressed and peaked by D14. These observations confirm that cardiac differentiation towards terminal cell lineage commitments was successful from STLV the culture-derived EBs.

Immunohistochemical analysis of cardiac outgrowth

To evaluate further the ability of cardiac outgrowth to form EBs from different groups (STLV1-4) outgrowths were immunostained with cTnT antibody (Fig. 5a) which marks cardiac lineage comitment. Expression of cTnT revealed the presence of an extensive and filamentous network at all examined timepoints (D2-5; Fig. 5a). The areas of expression of cTnT in the STLV3 and STLV4 groups was higher than in the other groups, with the STLV3 group showing the highest level of immunostaining (Fig. 5b). This confirms that the STLV3 treatment at D3 produces the most extensive cardiac network.

\section{In conclusion}

We have demonstrated that the optimized STLV bioreactor method provides satisfactory control over the agglomeration process of EBs, therefore enabling cell proliferation and differentiating ES cells towards cardiomyocytes. The starting number of ES cells in EBs, the rotation speed and the time of EB adherence onto gelatin-coated plates affected the cardiogenesis. A starting number of $3 \times 10^{5}$ ES cells plated on day 3 following rotation culture onto gelatin-coated surfaces results in the highest potential of cardiac differentiation. The ability to 
produce homogeneous populations of EBs of particular sizes also increases the differentiation potential of ES cells into cardiomyocytes. The establishment of this cultivation system provides a powerful research and clinical tool for several fields such as disease modeling and cardiac tissue engineering, as well as regenerative medicine applications

or drug screening tests. This methodology could also be employed to further our understanding of intrinsic EB properties and their effect on cell differentiation and lineage commitment.

\section{Acknowledgements}

This study was supported by EU Seventh Framework Programme (PartnErS, PIAP-GA-2008-218205; InduHeart, PEOPLE-IRG-2008-234390; InduStem, PIAP-GA-2008-230675; PluriSys, HEALTH-2007-B-223485; Resolve, FP7-HEALTH-F4-2008-202047); NKTH-OTKA-EU FP7-HUMAN-2009-MB08-C 80205 and NKTH/KPI (NKFP_07_1-ES2HEART-HU OM-00202-2007), CHE-TRF senior scholarship No. RTA 5080010 (M.T.) and the Thailand Commission on Higher Education (CHE-PhD-SW-2005-100 (S.R.), CHE-PhD-SW-2007 (N.K.)).

\section{Reference list}

Chen M, Lin YQ, Xie SL, Wu HF, Wang JF (2010) Enrichment of cardiac differentiation of mouse embryonic stem cells by optimizing the hanging drop method. Biotechnol Lett Dec 17

Dang SM, Kyba M, Perlingeiro R, Daley GQ, Zandstra PW (2002) Efficiency of embryoid body formation and hematopoietic development from embryonic stem cells in different culture systems. Biotechnol Bioeng 78:442-453

Dobrovolskaia-Zavadskaia N (1927). Sur la mortification spontanée chez la souris nouveau-née et sur l'existence d'un caractère (facteur) hereditaire, non-viable. Crit. Rev. Soc. Biol. 97:114 -119

Evans MJ, Kaufman MH (1981) Establishment in culture of pluripotential cells from mouse embryos. Nature 292:154-156 
Gerecht-Nir S, Cohen S, Itskovitz-Eldor J (2004) Bioreactor cultivation enhances the efficiency of human embryoid body (hEB) formation and differentiation. Biotechnol Bioeng. 86:493-502

Hwang YS, Cho J, Tay F, Heng JY, Ho R, Kazarian SG, Williams DR, Boccaccini AR, Polak JM, Mantalaris A (2009) The use of murine embryonic stem cells, alginate encapsulation, and rotary microgravity bioreactor in bone tissue engineering Biomaterials 30(4): 499-507

Kobolak J, Kiss K, Polgar Z, Mamo S, Rogel-Gaillard C, Tancos Z, Bock I, Baji AG, Tar K, Pirity MK, Dinnyes A (2009) Promoter analysis of the rabbit POU5F1 gene and its expression in preimplantation stage embryos. BMC Mol Biol 10:88-100

Höpfl G, Gassmann M, Desbaillets I (2004) Differentiating embryonic stem cells into embryoid bodies. Methods Mol Biol 254:79-98

Lü S, Liu S, He W, Duan C, Li Y, Liu Z, Zhang Y, Hao T, Wang Y, Li D, Wang C, Gao S (2008) Bioreactor cultivation enhances NTEB formation and differentiation of NTES cells into cardiomyocytes. Cloning Stem Cells 10:363-370

Magin TM, McWhir J, Melton DW (1992) A new mouse embryonic stem cell line with good germ line contribution and gene targeting frequency. Nucleic Acids Res 20:3795-3796

Martin, GR (1981) Isolation of a pluripotent cell line from early mouse embryos cultured in medium conditioned by teratocarcinoma stem cells. Proc Natl Acad Sci U S A 78:7634-7638

Ranganayakulu G, Elliott DA, Harvey RP, Olson EN (1998) Divergent roles for NK-2 class homeobox genes in cardiogenesis in flies and mice. Development 125(16):3037-3048 
Schuldiner M, Yanuka O, Itskovitz-Eldor J, Melton DA, Benvenisty N (2000) Effects of eight growth factors on the differentiation of cells derived from human embryonic stem cells. Proc Natl Acad Sci U S A 97:11307-11312

Schwartz R J, Olson EN (1999) Building the heart piece by piece: modularity of cis-elements regulating Nkx2-5 transcription. Development 126:4187-4192

Shamblott MJ, Bugg EM, Lawler AM, Gearhart JD (2002) Craniofacial abnormalities resulting from targeted disruption of the murine Sim2 gene. Dev Dyn 224:373-380

Yirme G, Amit M, Laevsky I, Osenberg S, Itskovitz- Eldor J (2008) Establishing a dynamic process for the formation, propagation, and differentiation of human embryoid bodies Stem Cells Dev 17: 1227-1241 


\section{Figure legends}

Fig. 1 The effect of the starting number of ES cells on efficiency of EB formation. a HM1 ES cell line exhibits typical gross morphology of mouse ES cells including a high nuclear/cytoplasmic ratio and round shape; b Schematic presentation of in vitro differentiation procedure in STLV culture system; c Gross morphology of EBs produced in different STLV systems; $\mathbf{d}$ The effect of the starting cell density of ES cells on the size of EB formation; e The effect of the starting cell density of ES cells on EB size. $10 \mathrm{ml}$ of STLV culture medium was passed through a $100-\mu \mathrm{m}$ cell strainer to separate cell aggregates constituting EBs from individual cells. In each group, EBs from $1 \mathrm{ml}$ of the total STLV culture medium volume was counted for investigating the yield EBs. Data presented as mean \pm SEM. The difference was considered significant for $\mathrm{a} * \mathrm{p}<0.05, * * \mathrm{p}<0.01$.

Fig. 2 The effect of the rotation speed of STLV on the efficiency of EB formation. a The effect of rotary speed on EB size; $\mathbf{b}$ The effect of rotary speed on the EB yield. Scale bars correspond to $500 \mu \mathrm{m}$. Data presented as mean \pm SEM. The difference was considered significant for a $\mathrm{p}<0.05, * \mathrm{p}<0.01 ; * * \mathrm{p}<0.001 ; * * \mathrm{p}<0.0001$.

Fig. 3 The effect of the starting number of ES cells and time of EB plating on subsequent cardiac differentiation. $\mathbf{a}$, b, c, d The beating extent of EBs from STLV3 and STLV4 plated at different time points (D2-D5) during differentiation (D5-D14); e, f, $\mathbf{g}, \mathbf{h}$ Grading of cardiomyocytes by scoring the number of beating areas and the beating strength.

Fig. 4 Quantitative real time polymerase chain reaction analysis of gene expression in STLV3 culture systems. Gene expression of a Pou5f1/Oct4; b Nkx2.5; c Tnnt2; d Myh6; e Myl2; f Nppa; and g Brachyury markers were assayed.

Fig. 5 The effect of starting number of ES cells and time of EBs adherence to gelatin-coated plate on expression of cTnT, a marker of cardiac differentiation. a Immunostaining of cardiomyocytes generated from STLV3 and STLV4; 
b Measurement of cTnT area from corresponding STLVs. The cells were stained with cTnT antibody (red) and DAPI (blue). 
Figures

Fig. 1
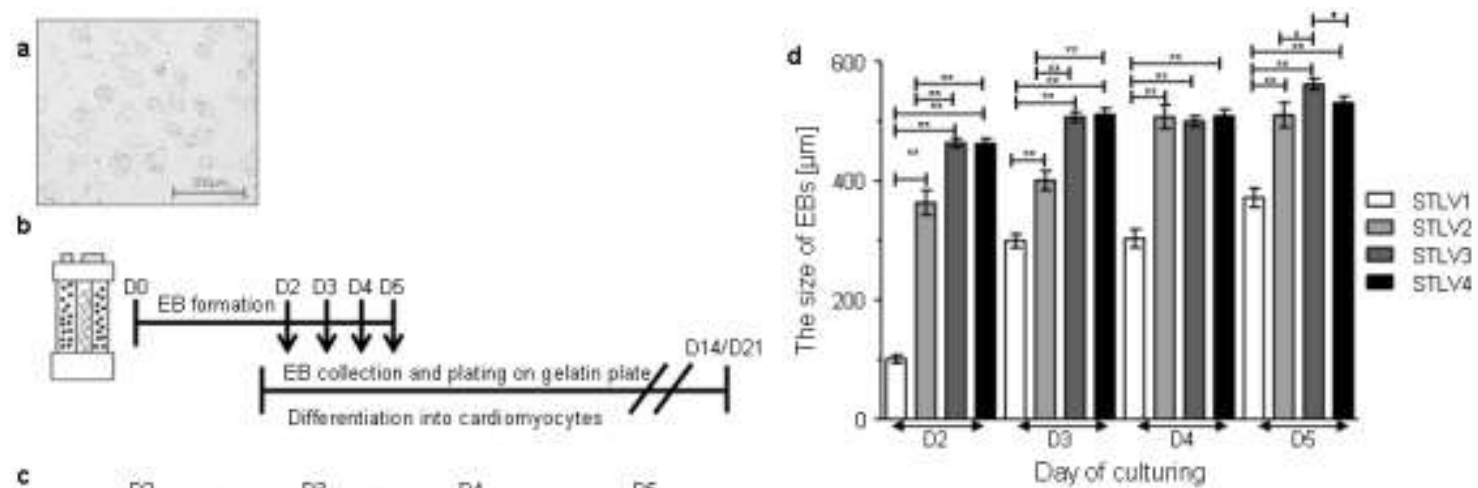

c
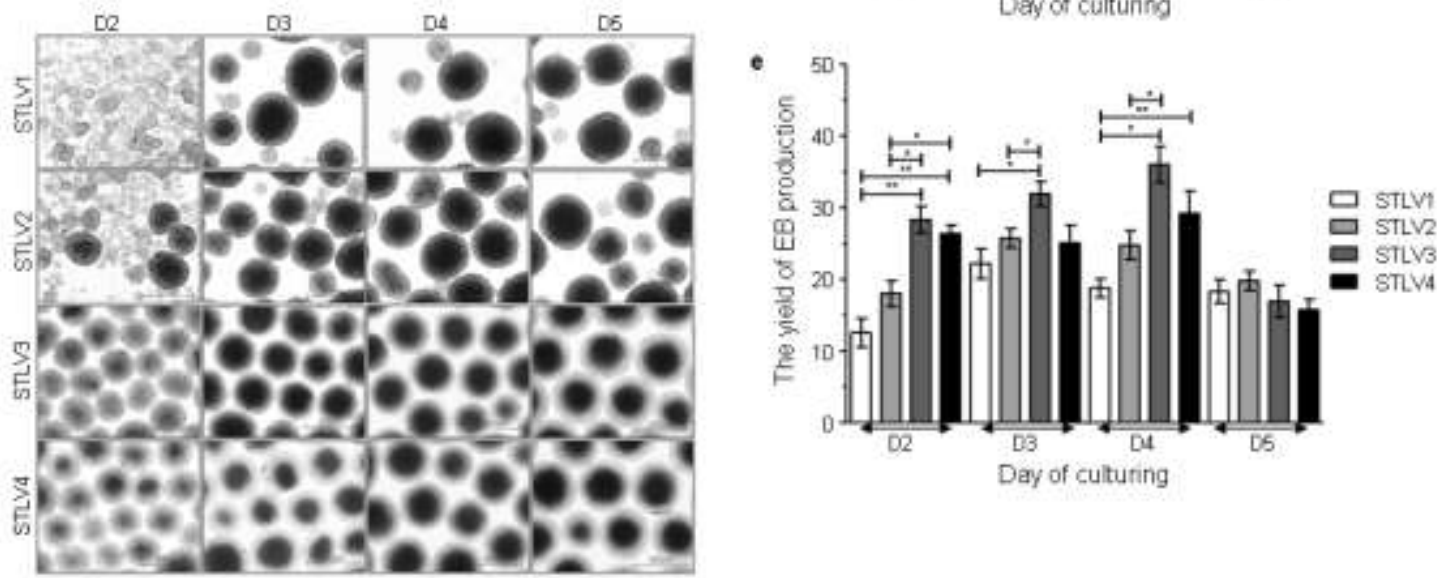
Fig. 2

a

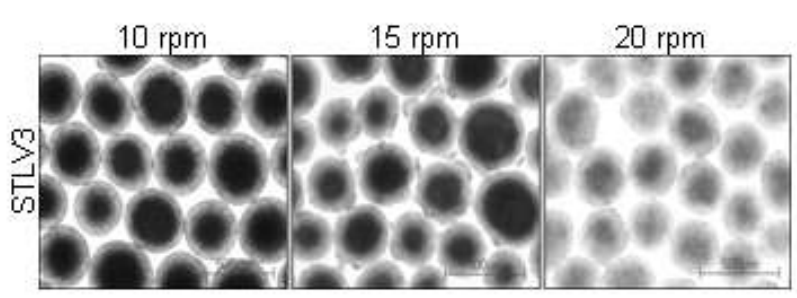

b
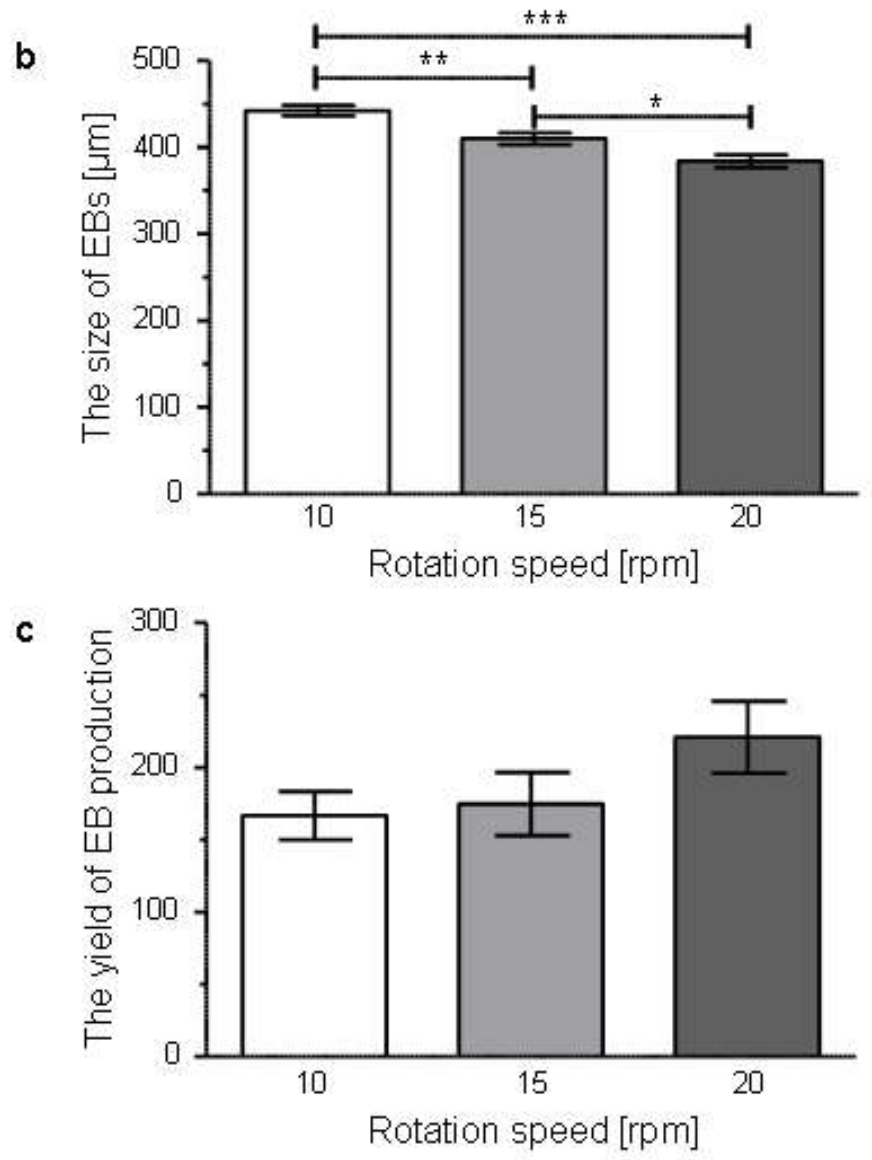
Fig. 3
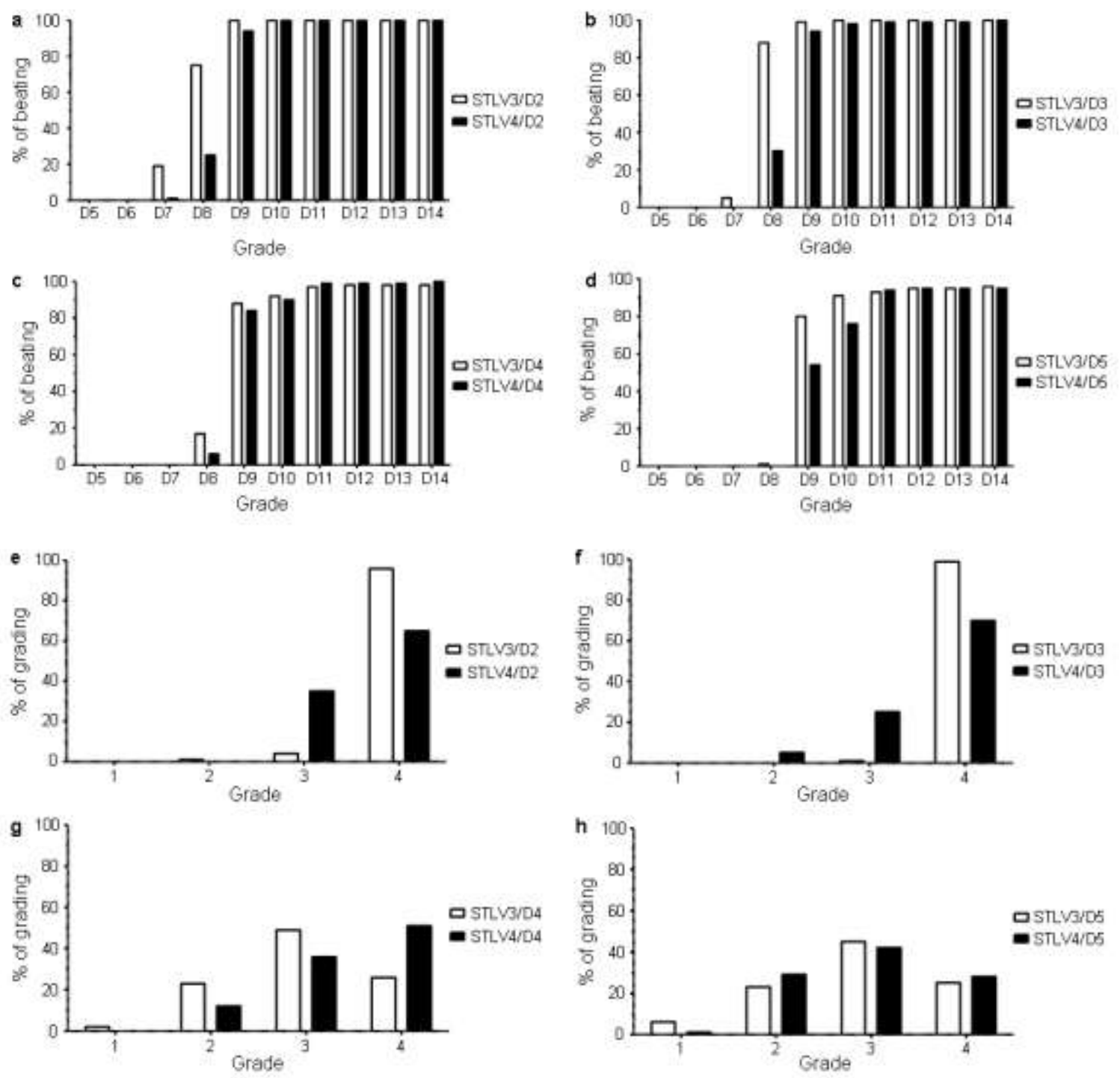
Fig. 4
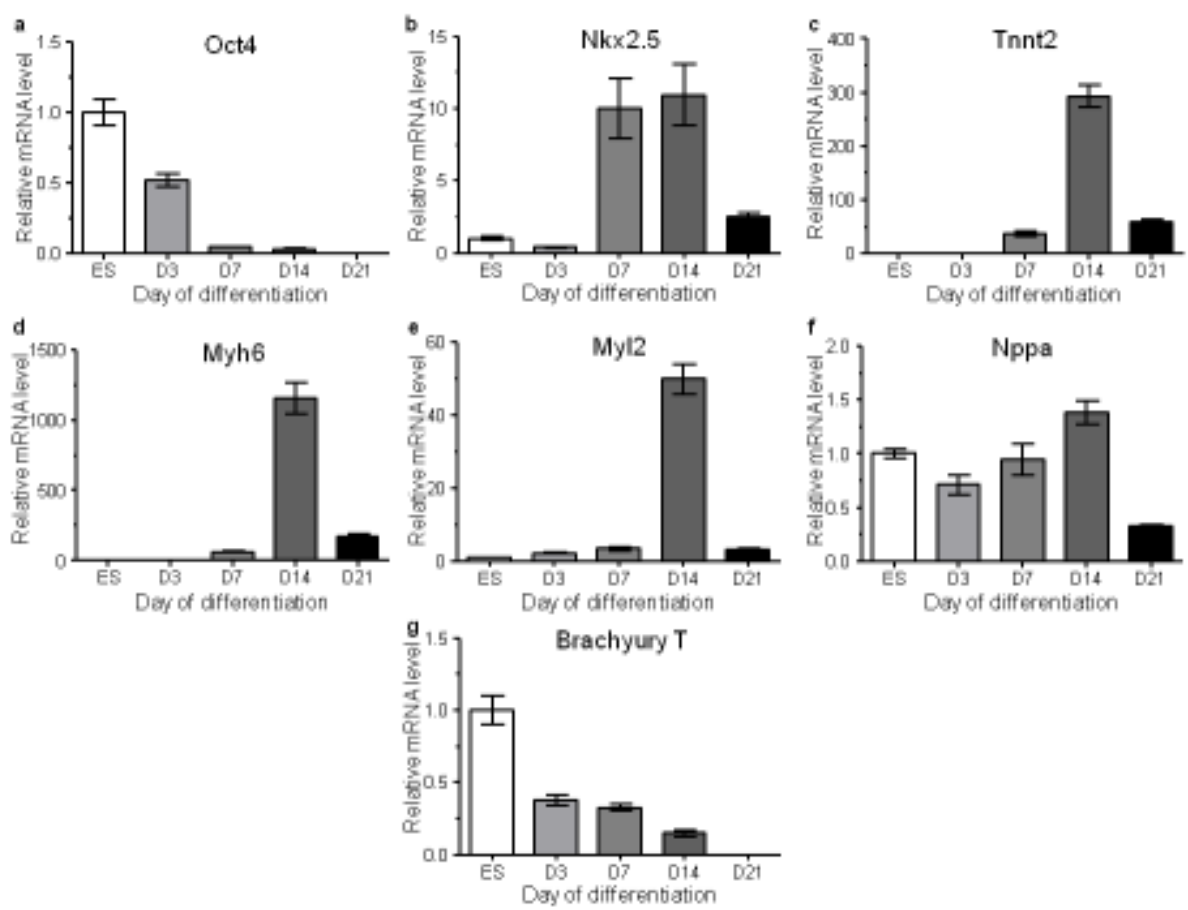
Fig. 5
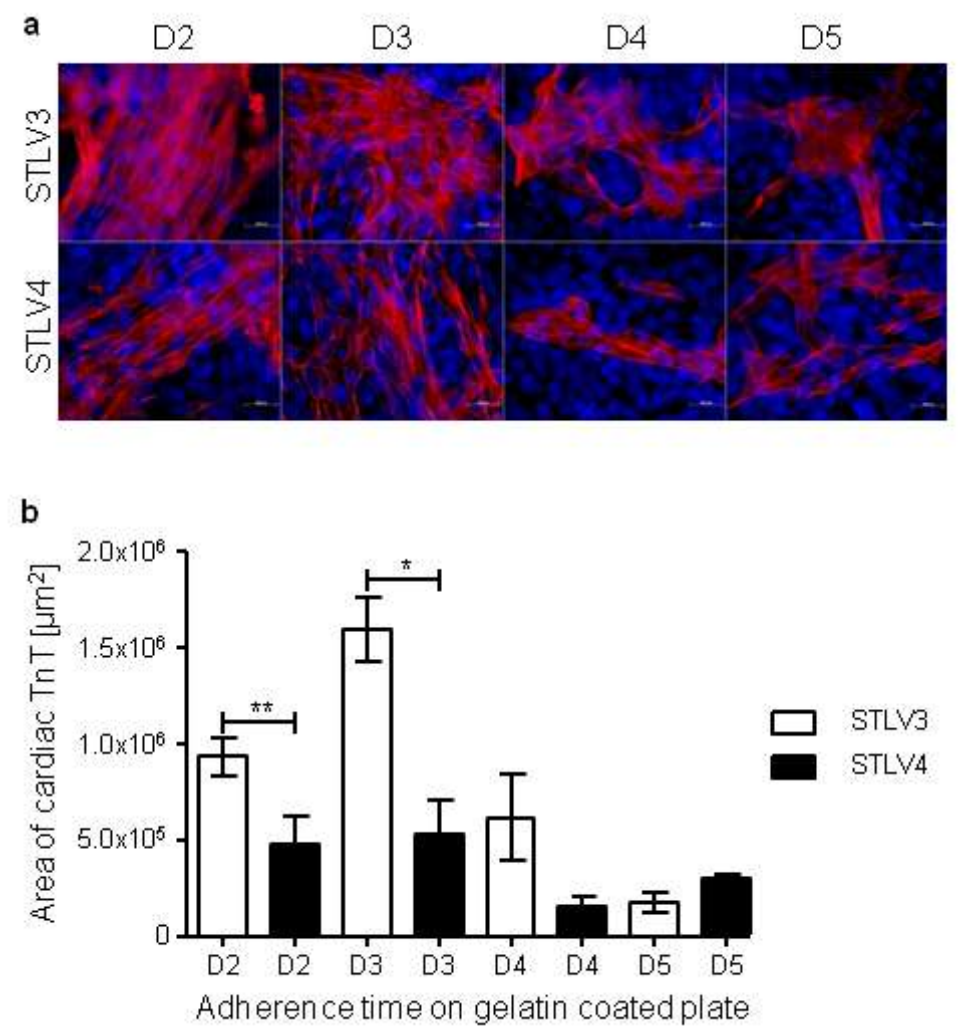